\title{
Implementação de um laboratório de realidade virtual de baixo custo: estudo de caso de montagem de um laboratório para o ensino de Matemática
}

\author{
Valéria Farinazzo Martins ${ }^{1}$ \\ Alisson José Gregório de Oliveira ${ }^{1}$ \\ Marcelo de Paiva Guimarães ${ }^{2}$
}

\begin{abstract}
Resumo: Este artigo relaciona os conceitos envolvidos na área de realidade virtual, educação e engenharia de software a fim de descrever os passos para a construção de um laboratório de realidade virtual de baixo custo, a partir de recursos computacionais pré-existentes em escolas que geralmente possuem um baixo orçamento para investimentos em laboratórios de informática. Os passos tratam das questões de hardware, de software e educacionais envolvidos na utilização de um laboratório de informática existente como um laboratório com aplicações de jogos educacionais de realidade virtual. Ao final deste trabalho, é apresentado um estudo de caso que demonstra a construção de um laboratório desses na área de Matemática, em uma escola pública de ensino médio, localizada na cidade de São Paulo. Realizou-se avaliação do estudo de caso a fim de notar a relevância do uso de realidade virtual como ferramenta complementar ao ensino tradicional (sala de aula). Este estudo de caso valida os passos sugeridos para esta implantação, garantindo sua viabilidade.
\end{abstract}

Palavras-chave: Ambientes virtuais. Educação. Laboratório computacional de baixo custo. Realidade virtual.

\begin{abstract}
This paper relates the concepts involved in Virtual Reality, Software Engineering, Education areas and it describes the steps to create low cost virtual reality laboratories for learning from existing labs in schools, which usually have low budgets. These steps treat aspects about hardware, software and pedagogical issues in order to change conventional computational laboratories in a space with virtual reality educational games. Finally, it presents a case study that demonstrates the construction of a laboratory to teach mathematics in a public high school, located in São Paulo. We conducted the assessment of a case study to note the relevance of Virtual Reality as a complementary tool to traditional teaching (classroom). This case study validates the steps suggested for this deployment, ensuring its viability.
\end{abstract}

Keywords: Education. Low Cost Laboratory. Virtual environments. Virtual reality.

\section{Introdução}

Segundo Burdea [1], realidade virtual (RV) é uma interface computacional avançada que envolve simulação em tempo real e interações, através de canais multissensoriais. Essa simulação ocorre por intermédio do uso de diversos dispositivos computacionais de entrada/saída, como, por exemplo, os de visualização 3D estereoscópicos, os de sensação de toque (dispositivos haptic) e os que capturam os movimentos dos usuários.

\footnotetext{
${ }^{1}$ Faculdade de Computação e Informática Universidade Presbiteriana Mackenzie, Rua da Consolação, 930 - São Paulo - SP Brasil

valeria.farinazzo@mackenzie.br, allissongrego@yahoo.com.br

${ }^{2}$ Universidade Federal de São Paulo/membro do Programa de Mestrado da Faculdade Campo Limpo Paulista, São Paulo, Brasil

marcelodepaiva@gmail.com
}

http://dx.doi.org/10.5335/rbca.2013.2810 
A RV permite que os usuários, por intermédio de simulações, manipulem situações reais, como a condução de um veículo, e imaginárias, como a navegação entre um planeta e outro em segundos. Assim, os benefícios da RV podem ser aplicados em diversas áreas do conhecimento; a Engenharia, por exemplo, pode reduzir ou evitar a construção de protótipos físicos, e simular ambientes inacessíveis ou perigosos. A Medicina pode utilizar a RV para interpretar dados, monitorar pacientes e planejar cirurgias.

A RV permite conhecer e descobrir lugares em que jamais seria possível estar. Ela possibilita manusear objetos que na vida real seriam impossíveis de serem manuseados, seja pelo peso ou pelas dimensões. Permite a visualização do mundo hoje ou há milhares de anos; permite a exploração de ambientes e objetos através de ambientes virtuais em forma de ambientes, fotos, gráficos, entre outros.

De acordo com Kalawsky [2] e Vince [3], entre outros, uma aplicação de RV típica deve agregar características que a tornem:

- Sintética: o ambiente é gerado em tempo-real por um sistema computacional (ele não é pré-gravado, como acontece, por exemplo, com sistemas de multimídia);

- Tridimensional (3D): o ambiente que cerca o usuário é representado em 3D, então, o usuário tem a sensação de que o ambiente possui profundidade e que se pode mover-se através dele;

- Multissensorial: mais de uma modalidade sensorial é usada para representar o ambiente, como sentido visual, sonoro, espacial (de profundidade) e de reação do usuário com o ambiente;

- Imersiva: o usuário tem a sensação de fazer parte do mundo sintético gerado. Normalmente, um sistema imersivo é obtido com o uso de capacetes de visualização ou telas ao redor do usuário, como, por exemplo, os sistemas de multiprojeção, mas outros sentidos, como o som e os controles reativos, são também importantes;

- Interativa: está ligada com a capacidade de o sistema computacional detectar as entradas do usuário e modificar instantaneamente o mundo virtual e as ações sobre ele;

- Realística: trata-se da precisão com que o ambiente virtual reproduz os objetos reais, as interações com os usuários e o próprio modelo do ambiente;

- Com presença: caracteriza-se como sendo um sentido subjetivo de que o usuário está fisicamente dentro do ambiente virtual.

O atendimento dessas características é essencial para a construção de aplicações de RV cada vez mais sofisticadas, ou seja, que possuam um grande número de recursos, alto nível de interação e imersão e, ao mesmo tempo, que satisfaçam os usuários. Não é necessário que todas essas características sejam exploradas ao máximo, porém, a ausência total de um desses itens pode comprometer a classificação do sistema como sendo de RV.

A educação é uma área que tem utilizado a RV para o desenvolvimento de novas metodologias de ensinoaprendizagem. As aplicações de RV criam a possibilidade de se obter um novo processo de exploração, observação e construção de uma nova visão do conhecimento, o que pode resultar aos estudantes a oportunidade de melhor compreensão do conteúdo em estudo. Isso se deve a pesquisadores e desenvolvedores que estão realizando experiências e testando recursos para melhorar a qualidade da educação [4].

A RV na educação cria possibilidades que permitem aos estudantes conhecer ambientes de difícil acesso ou remotos por meio de aplicações, como forma de melhorar a compreensão, estimulando, assim, o aprendizado dos estudantes.

Visto que as escolas geralmente possuem um baixo orçamento para investimentos em laboratórios, a necessidade de soluções que permitam a implantação de soluções de RV de baixo custo é clara para todos. O uso de poucos recursos financeiros nos projetos é crucial para a implementação efetiva destes. De forma geral, três pontos devem ser vistos para que isso aconteça:

- ambiente físico: refere-se à parte física, como o sistema de visualização, computadores e instalações em geral [5];

- ambiente lógico: engloba a disponibilidade de conteúdo e das ferramentas de desenvolvimento e execução, e os outros aplicativos [5]; 
- proposta educacional: tanto o ambiente físico quanto o lógico devem atender a estratégia pedagógica adotada.

Os maiores gastos geralmente se referem ao ambiente físico, pois necessariamente têm custo agregado, como, por exemplo, computadores com placas gráficas capazes de gerar aplicações interativas. Os gastos referentes à parte lógica (aplicativos) geralmente são baixos ou inexistentes, pois existem diversas soluções gratuitas disponíveis.

O uso efetivo de aplicações de RV até os últimos anos teve como barreira o alto preço dos equipamentos envolvidos e a falta de ferramentas de software. Os avanços tecnológicos atuais reverteram essa situação. Agora é possível trabalhar com tais aplicações com menos recursos e com uma variedade de soluções de software, de tal maneira que os requisitos específicos e gerais dessas aplicações são atendidos. Entende-se como requisitos específicos, por exemplo, a necessidade de geração de imagens com alta qualidade em um tempo mínimo, e como requisitos gerais, por exemplo, a baixa curva de aprendizagem dos desenvolvedores de aplicações de RV, ou seja, ferramentas fáceis de aprender e que permitem o desenvolvimento rápido de tais aplicações [5].

O intuito deste artigo é descrever como projetos de baixo custo podem ser implementados numa escola com poucos recursos financeiros disponíveis, tendo como base um laboratório de informática pré-existente e um apoio pedagógico. Então, optou-se pela criação de ambientes não imersivos, ou seja, aqueles que utilizam um monitor comum e no qual o estudante manipula o ambiente virtual através de um dispositivo de entrada convencional, como teclado e mouse. Serão detalhadas aqui todas as fases para a concretização de tais projetos.

No início desta pesquisa, procurou-se por aplicações de RV que estivessem sendo utilizadas em escolas, públicas ou privadas, no Brasil. Verificou-se que, nas escolas privadas, a maioria dos gestores se preocupou em não disponibilizar seus projetos em laboratórios para visitação, visto que envolvem uma quantia bastante importante de recursos financeiros. Por outro lado, diversos artigos científicos encontrados na literatura propunham a construção de ambientes virtuais para o auxílio de disciplinas existentes no ensino fundamental e médio, tais como química, física e matemática $[6,7,8]$ - mas esses projetos não foram, de fato, implementados em escolas para que se fosse possível a realização de uma avaliação formal destes, em relação ao aprendizado, custos, eficácia, eficiência e usabilidade. O que se percebeu foram projetos concebidos sem a união da área tecnológica e educacional. Neste artigo será apresentado um estudo de caso que demonstra os resultados práticos de uma implantação de um laboratório de RV, incluindo este envolvimento da área educacional.

Este artigo está estruturado da seguinte maneira. Na seção 2 são apresentadas as fundamentações teóricas que serviram de base para a elaboração do trabalho. Nela discute-se o ambiente físico e lógico envolvido, além disso, o uso de RV na educação. A seção 3 versa sobre a metodologia utilizada para a implementação de um projeto de baixo custo na transformação de um laboratório de informática em um laboratório de RV. Na seção 4 é apresentado um estudo de caso que valida a metodologia exposta na seção 3 . Na seção 5 são apresentados os resultados deste projeto. Finalmente, na seção 6, estão as conclusões do trabalho.

\section{Fundamentação teórica}

Nesta seção serão apresentados os conceitos relacionados aos ambientes físico e lógico de RV, RV na área educacional, assim como os trabalhos relacionados.

\subsection{Ambiente físico de realidade virtual}

Um laboratório físico de RV pode ser dividido em quatro partes:

- ambiente físico (iluminação, ar condicionado, eletricidade, área);

- sistema computacional de processamento (hardware);

- sistema de visualização (dispositivos de saída: incluindo vídeo, áudio, retorno tátil, entre outros);

- sistema de interação (dispositivos de entrada: joysticks, trackers, câmeras, entre outros).

Como a ideia deste trabalho é a de se utilizar um laboratório de informática pré-existente, então a proposta é que não haja ou seja pouca a modificação no ambiente. Isso geralmente é possível, desde que o

Revista Brasileira de Computação Aplicada (ISSN 2176-6649), Passo Fundo, v. 5, n. 1, p. 98-112, abr. 2013100 
hardware seja capaz de suportar as entradas/saídas e processamento desejados e que o software realize a integração requerida [9]. Cabe ressaltar que o gargalo (bottleneck) relacionado aos recursos físicos nas aplicações de RV comumente é a capacidade de processamento gráfico [5]. Assim, sugere-se, se possível, que os computadores possuam placas aceleradoras de vídeo (placas gráficas).

O ambiente físico deve favorecer a imersão e interação dos usuários. A imersão, que é a capacidade de fazer com que o usuário se sinta como parte do mundo virtual, é proporcionada por intermédio de dispositivos como monitor com imagens em 3D e som (em um ambiente convencional). A interação pode ser realizada por dispositivos como mouse e joystick. É fato que esses dispositivos convencionais são pouco práticos para algumas aplicações de RV, provendo uma forma não intuitiva de manipulação do mundo e restringindo o usuário a uma mesa fixa e entradas bidimensionais. Porém, eles são suficientes para várias aplicações, como é o caso do estudo de caso apresentado neste artigo.

Um ponto de destaque em diversos laboratórios com recursos financeiros limitados encontrados na literatura é a criatividade e empenho dos envolvidos, como, por exemplo, o CaveUT [10]. Em tais soluções é comum o uso de meios de interação alternativos a fim de substituição de dispositivos não convencionais (rastreadores, luvas), como é o exemplo de uso de câmeras no lugar de rastreadores e o uso de comandos de voz, que, além de substituir, não exige hardware específico, e libera as mãos e braços dos usuários para outras tarefas.

Outro exemplo de tal criatividade, que pode resultar em um laboratório de destaque, é o mini-CAVE apresentado por Dias [11]. A Figura 1 apresenta o mini-CAVE, construído com dispositivos convencionais, que é um sistema composto por três telas. A solução é utilizada para o ensino de Odontologia. O uso dessas telas resulta em um alto grau de imersão. Ele utilizou wii-remote (controle principal do console da Nintendo Wii) para interagir com o ambiente. A construção de um ambiente como esse é mais complexa do que a abordada neste artigo, pois exige conhecimentos, como calibragem de equipamentos e de processamento de alto desempenho, pois as imagens de cada tela são renderizadas (geradas) por um cluster de computadores (conjunto de computadores).

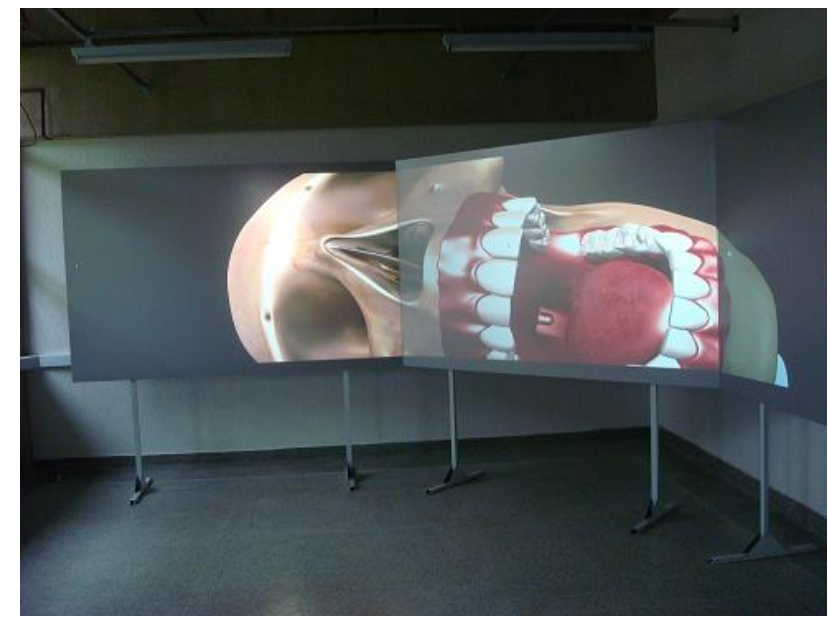

Figura 1: Mini-Cave construído com equipamentos convencionais [11]

\subsection{Ambiente lógico de realidade virtual}

A parte lógica de um ambiente de RV é composta por:

- Ferramentas de modelagem: são aplicações que permitem a criação de conteúdos. Um exemplo sem custo é a ferramenta Blender [12], que oferece uma gama de recursos e funcionalidades para criação de objetos 3D, renderização de cenas, animação com um editor de vídeo integrado e pósprodução, tudo em um único ambiente de trabalho. Ela está disponível para várias plataformas, como Microsoft Windows, Mac OS X, GNU/Linux, IRIX, Solaris, FreeBSD, SkyOS e MorphOS. Essa ferramenta high-end fornece funcionalidades similares às encontradas em soluções comerciais como XSI [13], Cinema 4D [14], 3D Studio Max [15] e Maya [16]. 
- Ferramentas de desenvolvimento: são soluções que fornecem facilidades para a construção de aplicações de RV. Diversas ferramentas de desenvolvimento sem custo estão disponíveis, como é o exemplo do Panda-3D [17] e do OGRE [18].

A evolução dessas soluções tem sido constante, oferecendo um maior realismo gráfico, suporte a formas mais avançadas de animação e facilidades de programação, como ambientes visuais e os baseados em scripts (interpretação de comandos) [5].

Uma ferramenta ideal de desenvolvimento é aquela que, além de resolver os problemas pertinentes às aplicações de RV como a geração de imagens de alta qualidade, atenda os requisitos básicos de software, como: usabilidade, suporte a novas tecnologias, desempenho, fácil manutenção, tolerância a falhas, portabilidade e reusabilidade.

Um ponto, e talvez o mais difícil de ser resolvido, é a necessidade de um profissional de Computação no laboratório de RV. O papel desse profissional deve ser o daquele que promove o desenvolvimento de aplicações, a customização/instalação de soluções disponíveis e treinamento dos professores. No mínimo, os dois últimos papéis devem ser atendidos, visto que se houver um repositório de objetos de aprendizagem de RV efetivo, o primeiro requisito de desenvolvimento não será necessário. Esse profissional tem como tarefa cotidiana a busca e o desenvolvimento de novos conteúdos. Além disso, é primordial a atuação dele de maneira sincronizada com a equipe pedagógica de tal forma que a tecnologia sirva como estímulo aos estudantes e que o objetivo principal, que é a aprendizagem, seja alcançado [19].

\subsection{Realidade virtual na educação}

Educação engloba o ensino e o aprendizado e é um fenômeno observado em todas as sociedades e em grupos, responsável pela manutenção e perpetuação transpondo a gerações, modos culturais, convivência e respeito, seja em grupo ou em sociedade. Esse processo de socialização é exercido no convívio social onde o indivíduo está inserido. Tratando-se da educação formal (prática educativa observada em instituições específicas que seja de forma intencional e com objetivo determinado), e cabe às escolas ou instituições de ensino disponibilizar recursos técnicos e tecnológicos, através de ferramentas, de uma determinada comunidade para o desenvolvimento do ensino.

Freire [20] constatou que "Educar é construir, é libertar o homem do determinismo, passando a reconhecer o papel da História e onde a questão da identidade cultural, tanto em sua dimensão individual, como em relação à classe dos estudantes, é essencial à prática pedagógica proposta". Prossegue o autor destacando que "Sem respeitar essa identidade, sem autonomia, sem levar em conta as experiências vividas pelos estudantes antes de chegar à escola, o processo será inoperante, somente meras palavras despidas de significação real. A educação é ideológica, mas dialogante, pois só assim pode se estabelecer à verdadeira comunicação da aprendizagem entre seres constituídos de almas, desejos e sentimentos".

Educação é um processo para exploração, observação, descobrimento e construção do conhecimento de uma geração que apresenta resultados para a geração seguinte e assim sucessivamente.

Os avanços tecnológicos na área computacional têm introduzido a RV à sociedade de um modo geral, desmistificando o seu uso e incentivando pesquisas. A RV é uma área promissora e que todo o incentivo seja ele cultural ou tecnológico são de grande valia.

Atualmente, ao se falar em RV na Educação, a primeira aplicação que se pode pensar é em educação a distância. Porém, esta é apenas uma das possibilidades de uso de RV. Existem sistemas de imersão total ou parcial, visitação de museu, escolas, teatros e jogos educativos, entre outros, onde o usuário realmente pode interagir e vivenciar a realidade desses ambientes todos educativos [21].

Pode-se pensar também no uso de RV para estimular a aprendizagem significativa e o desenvolvimento do raciocínio do estudante devido à interação que os sistemas virtuais fornecem aos estudantes. Este tem sido um apelo de educadores e estudantes para facilitar a interação entre eles e o gosto pelos estudos, bem como a facilidade e a retenção de conhecimento proporcionado pela leitura e interação dos fatos.

$\mathrm{O}$ processo de RV na educação ainda é incipiente, porém, existe um consenso de que essa tecnologia ajuda na educação, pois as aplicações disponíveis são muitas e os benefícios claros na busca de soluções para resolver alguns dos problemas vividos na educação.

Revista Brasileira de Computação Aplicada (ISSN 2176-6649), Passo Fundo, v. 5, n. 1, p. 98-112, abr. 2013102 
A RV não é apenas uma ferramenta, mas é também uma forma de aprender e modernizar áreas em que a mesma seja inserida. Ela tem sido cogitada para um uso, de maneira intensa, no contexto educacional nos últimos anos.

\subsection{Trabalhos relacionados}

Foram encontrados, na literatura, alguns projetos que focam o desenvolvimento de ferramentas e software para baixo custo em diversas áreas do conhecimento, aos quais serão descritos os pontos e processos relevantes para execução deste trabalho.

- Guimarães e Gnecco [5] apresentaram soluções de baixo custo para o desenvolvimento de aplicações de RV e realidade aumentada com alto grau de imersão e interação. Discutem os desafios de implementação desses sistemas, desmistificando a reputação de serem caros e complexos. Abordam uma visão geral da especificação, instalação e configuração de vários sistemas computacionais, como dos multiprocessados e dos clusters de computadores. Por fim, apresentam exemplos de aplicações desenvolvidas.

- Santos e Machado [22] apresentaram um visualizador tridimensional de baixo custo para aplicações na Medicina, utilizando sistema operacional Linux e linguagens de código aberto. Procuraram conceber e integrar a um pacote de desenvolvimento de sistemas de simulação e treinamento médico uma classe que permitisse o uso do método de anaglifos coloridos. Dessa forma, o conjunto de bibliotecas ao qual essa classe foi integrada permitiu desenvolver aplicações de simulação que podem ser executadas em plataformas computacionais populares com visualização tridimensional colorida das imagens.

Porém, assim como os demais projetos citados nesse artigo (Jacobson [10], Dias [11] e Santos [22]) não focam na implementação de projetos de maneira concreta, não apresentando os passos para se alcançar o sucesso das aplicações com os usuários finais.

\section{Passos para implantação de RV em laboratórios com poucos recursos financeiros}

Como citado anteriormente, o objetivo central deste trabalho é o aproveitamento do laboratório de informática existente sem a captação de recursos financeiros. Para a construção efetiva de laboratórios como os propostos neste trabalho são necessários os seguintes passos:

- Passo 1: análise do ambiente físico pré-existente;

- Passo 2: estudo de forma clara e profunda dos conceitos envolvidos sobre RV (equipe técnica de computação, pedagógica e professores);

- Passo 3: análise da viabilidade de transformação do laboratório de informática pré-existente em um laboratório de RV; definição do conteúdo e da estratégia pedagógica a ser utilizada; teste dos aplicativos e dos equipamentos disponíveis;

- $\underline{\text { Passo 4: }}$ instalação, configuração dos aplicativos de RV e treinamentos dos professores e monitores;

- Passo 5: definição das ferramentas de avaliação do uso do laboratório, como questionários para analisar e levantar as necessidades dos usuários (estudantes e professores) em relação aos sistemas virtuais.

No diagrama de atividades da Figura 2 são descritos os passos para a transformação de um laboratório de informática comum em um laboratório de RV. Como primeiros passos, paralelamente, ocorre a análise do ambiente físico (passo 1) e do conteúdo educacional a ser abordado (passo 2). Nota-se a necessidade de um trabalho em conjunto da equipe técnica com a educacional. Isso servirá como base para a definição da estratégica pedagógica e dos aplicativos a serem utilizados (passo 3). Em seguida, pode ocorrer a implantação dos aplicativos e o treinamento dos professores (passo 4). Por fim, o laboratório de RV pode ser utilizado para o ensino. Nesse passo é importante uma avaliação continuada da aprendizagem resultante, assim, torna-se possível uma nova análise continuada da estratégia e dos aplicativos utilizados (passo 5). 


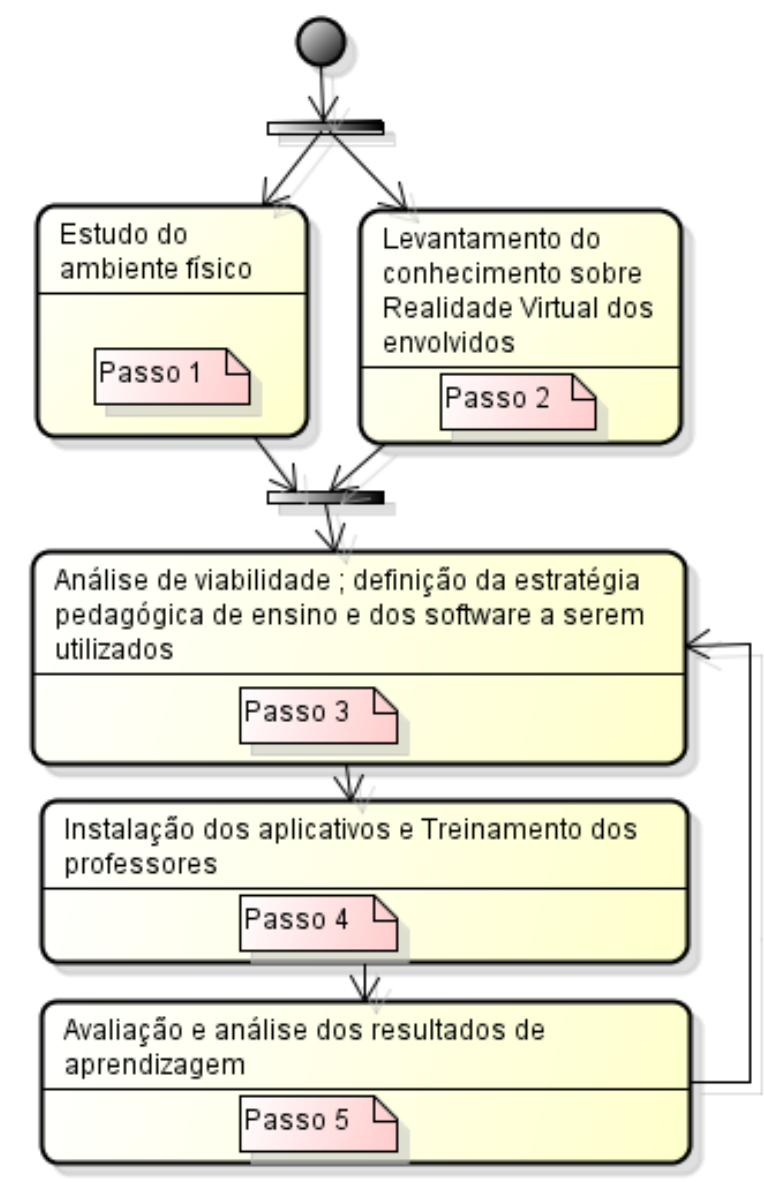

Figura 2: Passos para a implantação do laboratório de RV

\section{Estudo de caso}

A aplicação desta proposta ocorreu em uma escola pública estadual de ensino médio da cidade de São Paulo. A ação se iniciou com um estudo das necessidades da escola. A seguir, foi realizado o levantamento físico do laboratório pré-existente (passo 1). Em paralelo, foram desenvolvidos dois questionários, sendo o primeiro deles voltado para obter informações relacionadas aos estudantes (passo 2), o que permitiu o mapeamento das seguintes informações:

- faixa etária e grau de escolaridade dos estudantes;

- conhecimento prévio de RV;

- quais disciplinas os estudantes acreditavam que tinham maior relação com Informática;

- aceitação da informática como forma de aprendizado dinâmico e motivador;

- conhecimento do estudante sobre os custos com RV em um projeto na escola.

O segundo questionário voltou-se para um grupo de 20 professores e equipe pedagógica, e permitiu obter as seguintes informações:

- perfil do professor (disciplina ministrada, situação profissional e período);

- conhecimento do professor sobre os recursos de informática disponíveis na escola;

- quais os recursos de informática eram utilizados por eles, apoio técnico e facilidades de acesso; 
- uso de tecnologia para apoiar as atividades;

- conhecimento sobre RV;

- percepção sobre a questão se a RV pode ser útil na interação entre o estudante e a disciplina;

- percepção sobre a questão se a RV melhoraria o aproveitamento do estudante na disciplina.

Com base na entrevista com os professores, no questionário com os estudantes e na reunião com a equipe pedagógica verificou-se, então, uma oportunidade de implantação do laboratório de RV para tratar a área de Matemática. Além disso, ocorreu a análise dos recursos que possibilitariam a transformação do laboratório de informática em laboratório de RV e a definição da estratégia pedagógica (passo 3). Assim foi necessário verificar:

- ambiente físico: analisou-se o ambiente a fim de garantir o acesso dos estudantes e professores aos computadores; além disso, o acesso de todos aos aplicativos foi verificado, no caso, disponibilidade da internet, pois as aplicações poderiam estar em um repositório de objetos de RV na internet;

- sistema computacional de processamento: os testes de desempenho foram realizados no sistema a fim de garantir que o acesso, a navegabilidade e a interação seriam suficientes para o uso;

- sistema de visualização: o dispositivo de interação determinado foram os próprios monitores já disponíveis; apesar de não serem imersivos, permitem a visualização em 3D;

- sistema de interação: a fím de utilizar os recursos já disponíveis e aproveitar o conhecimento prévio dos usuários, foram escolhidos, como dispositivos de interação, o próprio teclado e o mouse dos computadores.

Os detalhes do ambiente físico referente ao parque tecnológico (computadores do laboratório de Informática) são descritos a seguir:

- computadores: a escola dispõe de 12 microcomputadores;

- sistema operacional: Windows Vista Home Basic;

- processador: Intel Celeron;

- disco rígido: $160 \mathrm{~GB}$;

- vídeo: 512 MB de memória dinâmica;

- memória: $1 \mathrm{~GB}$.

Os questionários proporcionaram conhecimento suficiente do problema para a determinação do conteúdo pedagógico a ser abordado. A análise do laboratório comprovou que os equipamentos eram suficientes para atender aos objetivos do projeto proposto. Nesse momento, partiu-se para a definição da estratégia pedagógica e do software a ser implantado.

Definiu-se como estratégia pedagógica utilizar o laboratório de RV como complemento das atividades realizadas em sala de aula. Determinou-se que os professores envolvidos iriam ministrar o conteúdo inicialmente em sala de aula, e, logo após, levariam os estudantes no laboratório para usufruir dos recursos computacionais. Por fim, os professores aplicariam em sala algum instrumento de avaliação de aprendizagem.

Após uma busca na internet por softwares de Matemática, foi adotado o GEO-3D (passo 4), por se tratar de um jogo com a finalidade de ensinar Matemática e por tratar o assunto escolhido (geometria espacial). Outro fator importante é o fato do software estar disponível para acesso sem custo e sem a necessidade de licença de acesso [23].

O GEO-3D foi desenvolvido em VRML (Virtual Reality Modelling Language), que é uma linguagem que descreve cenas em 3D e é utilizada para criar ambientes tridimensionais. A característica multiusuário da linguagem permitiu a participação de vários estudantes ao mesmo tempo no aplicativo, o que também motivou a sua escolha [24].

Esse software tem como finalidade instruir o estudante sobre geometria espacial. Nele, o estudante entra em uma sala virtual com duas portas, uma vermelha e outra azul, e um quadro contendo a descrição da pergunta 
que ele deve responder, baseada num objeto geométrico. A partir da escolha que o estudante realiza, ele é direcionado a outro ambiente similar, através de uma das portas. Isso se repete até que o estudante encontre uma mensagem informando o fim da tarefa. Existe somente um caminho que leva à vitória e à finalização do jogo. Portanto, pela estratégia do GEO-3D, assume-se que o estudante teve contato anteriormente com o conteúdo. Dessa maneira, ele atua como um exercício de fixação de conteúdos vistos em sala.

A Figura 3 apresenta uma cena que é composta por um quadro, no qual está escrita uma pergunta aos estudantes a fim de fornecer duas opções a ele: no caso entrar na porta azul ou na porta vermelha conforme a resposta à indagação.

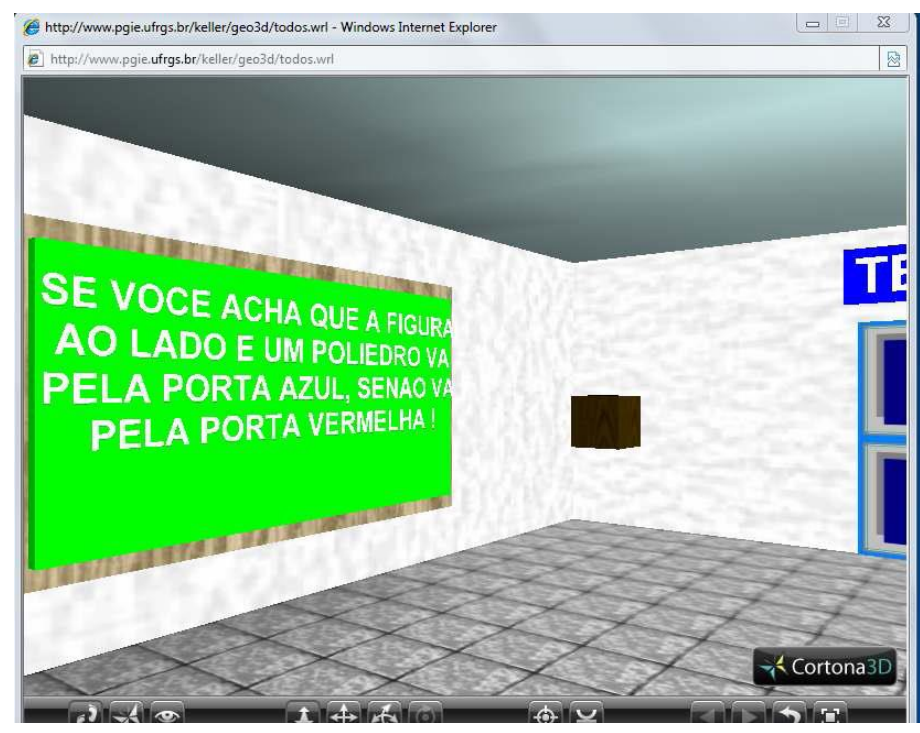

Figura 3: Pergunta apresentada ao estudante

A Figura 4 apresenta uma cena na qual o estudante navega em direção à porta azul.

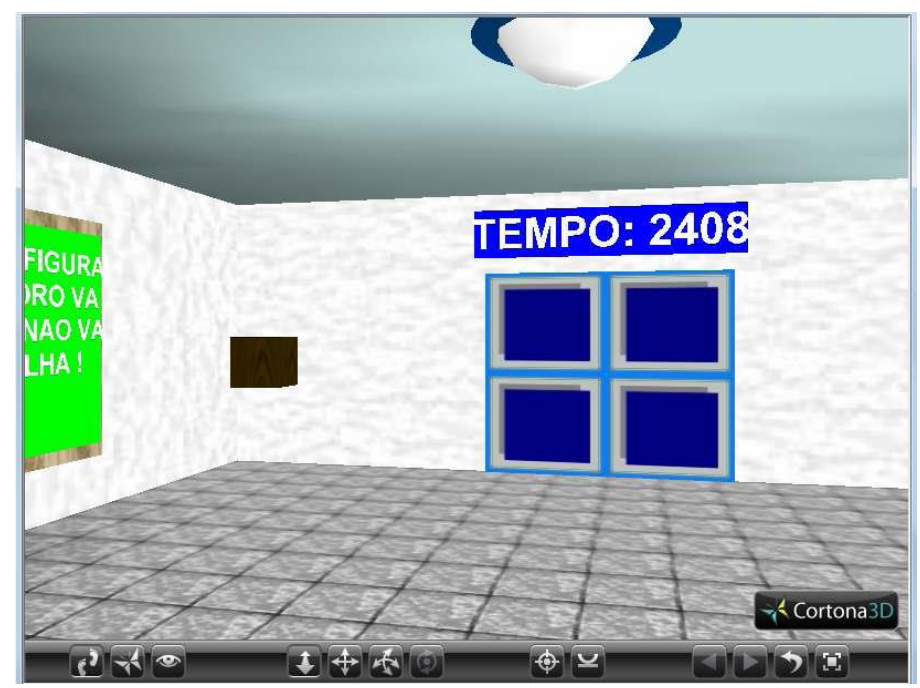

Figura 4: Navegação em direção à porta azul.

Com o objetivo de avaliar a proposta (passo 5) e, consequentemente, fornecer subsídios novos para a implantação do laboratório de RV, criou-se novamente dois questionários. O primeiro questionário foi aplicado a 70 estudantes do ensino médio e, buscou-se investigar a usabilidade da aplicação, baseado nas premissas de Nielsen [25], e também em questão ao aprendizado. Esses questionários buscavam respostas qualitativas e se basearam na escala Likert [26]. A seguir são apresentadas as questões avaliadas:

- possui interface agradável, fácil de usar; 
- o software é motivador;

- possui ajuda online ou offline;

- a interface apresenta clareza e consistência de forma apropriada para o uso;

- possui navegação intuitiva, simples e eficiente;

- você percebe a necessidade de suas ações para atingir seu objetivo;

- os enunciados e mensagens são claras e fáceis de serem entendidas;

- utiliza estratégia de reforço positivo para respostas certas;

- você voltaria a utilizar este software novamente.

Já para os professores, as questões apontavam questões didático-pedagógicas:

- o software apresenta boa legibilidade, clareza e consistência de forma apropriada aos estudantes?

- o software utiliza-se de ilustrações, animações, cores, recursos sonoros, em boa medida?

- trabalha os conteúdos de forma gradativa, caminhando do conhecimento básico ao conhecimento profundo de forma suave?

- contribui para a construção do processo de desenvolvimento e aquisição de competências e habilidades por parte do estudante?

- o software auxilia o estudante em seu desenvolvimento e convivência social?

- o software contribui para a conduta dos estudantes?

- o software auxilia no conteúdo ensinado em sala de aula?

- procura incentivar e conduzir o estudante sempre às respostas corretas, sem dar muito destaque aos erros cometidos pelo estudante?

- os enunciados e mensagens são claros e fáceis de serem entendidas?

- qual a sua opinião geral sobre o software?

\section{Avaliação dos resultados}

Através dos instrumentos de avaliação pré e pós-testes, ocorrida com a aplicação de questionários a trinta professores e setenta estudantes, ${ }^{3}$ foi possível delinear o perfil desses grupos (pré-testes) e também critérios de usabilidade (pós-testes).

\subsection{Questionários de pré-teste}

Aplicando os questionários de pré-teste, foi possível descobrir a respeito dos setenta estudantes:

- A faixa etária dos estudantes (Gráfico 1).

\footnotetext{
${ }^{3}$ Esses estudantes frequentam o laboratório de informática da escola nos finais de semana em razão do Programa Escola da Família, programa do governo do estado de São Paulo, executado pela Secretaria de Educação paulista, sobre a coordenação - da Fundação para o Desenvolvimento da Educação (FDE). Esse programa proporciona a estudantes universitários a possibilidade de custear seu curso com uma bolsa integral, prestando serviço aos finais de semanas nas escolas públicas conveniadas do estado de São Paulo. Outro objetivo é promover a inclusão digital aos estudantes e professores da escola pública estadual, através da internet, interação do estudante com o professor, prestação de serviço entre outras vertentes.
} 


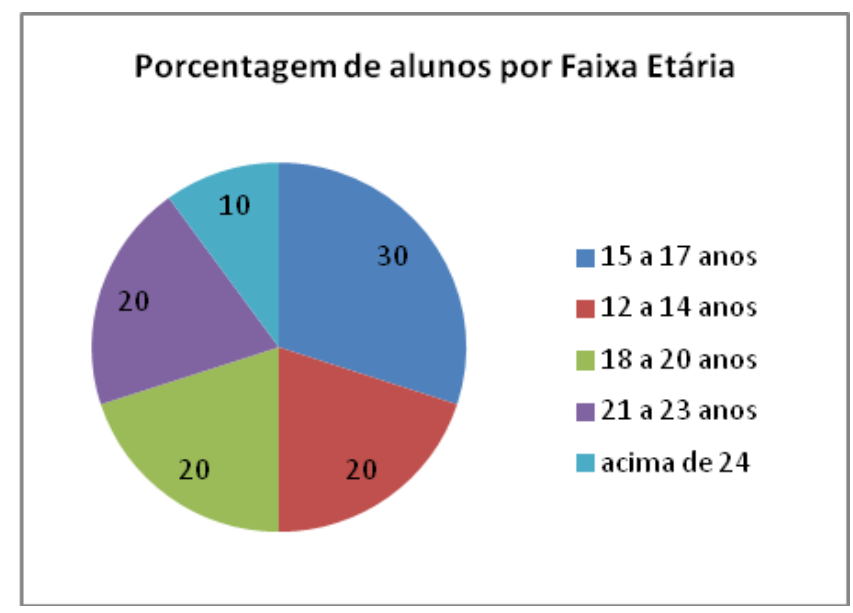

Gráfico 1: Faixa etária dos estudantes

- Que 53\% dos estudantes dizem conhecer o conceito de realidade virtual;

- Que os estudantes acreditam que Matemática é a matéria que mais tem relação com RV e que Português é a segunda (Gráfico 2).

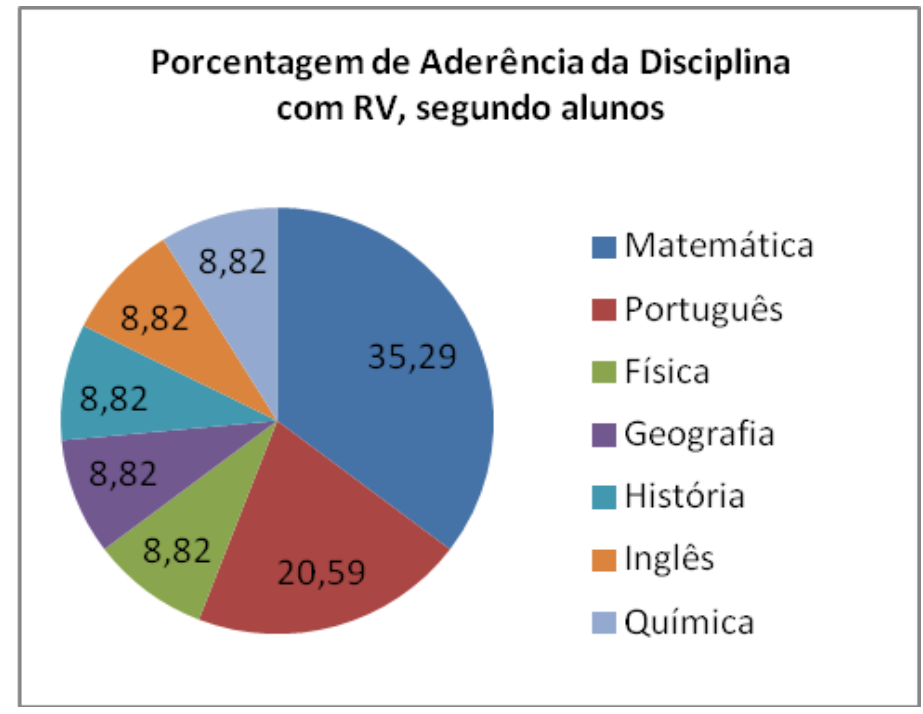

Gráfico 2: Relação da Matemática com RV

- Que 93\% dos estudantes acreditam que utilizar dispositivos computacionais nas aulas tornaria a aula mais dinâmica e motivadora;

- Que 95\% dos estudantes acreditam que seu próprio desempenho nas disciplinas melhoraria se eles utilizassem dispositivos computacionais para auxiliar o aprendizado;

- Que $70 \%$ dos estudantes acreditam que a escola pública tem como custear equipamentos de RV para uso dos estudantes;

- Que $40 \%$ dos estudantes acreditam que o investimento necessário com os equipamentos de RV seria entre 11.000 e 20.000 reais (Gráfico 3). 


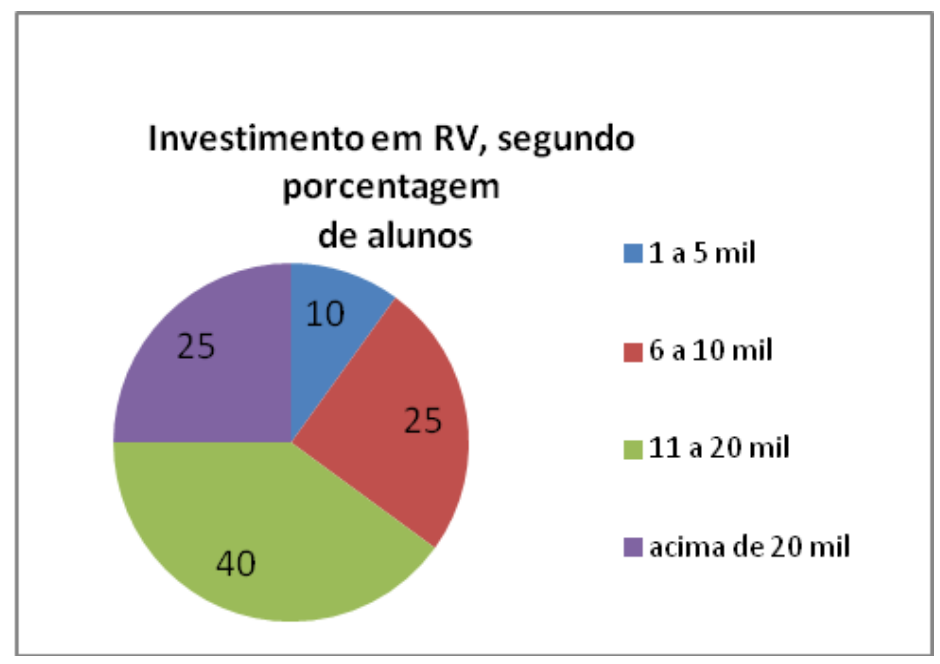

Gráfico 3: Investimento em RV

Já em relação ao perfil dos trinta professores constatou-se que:

- Havia professores das mais diversas áreas do ensino médio, com a distribuição apresentada no Gráfico 4.

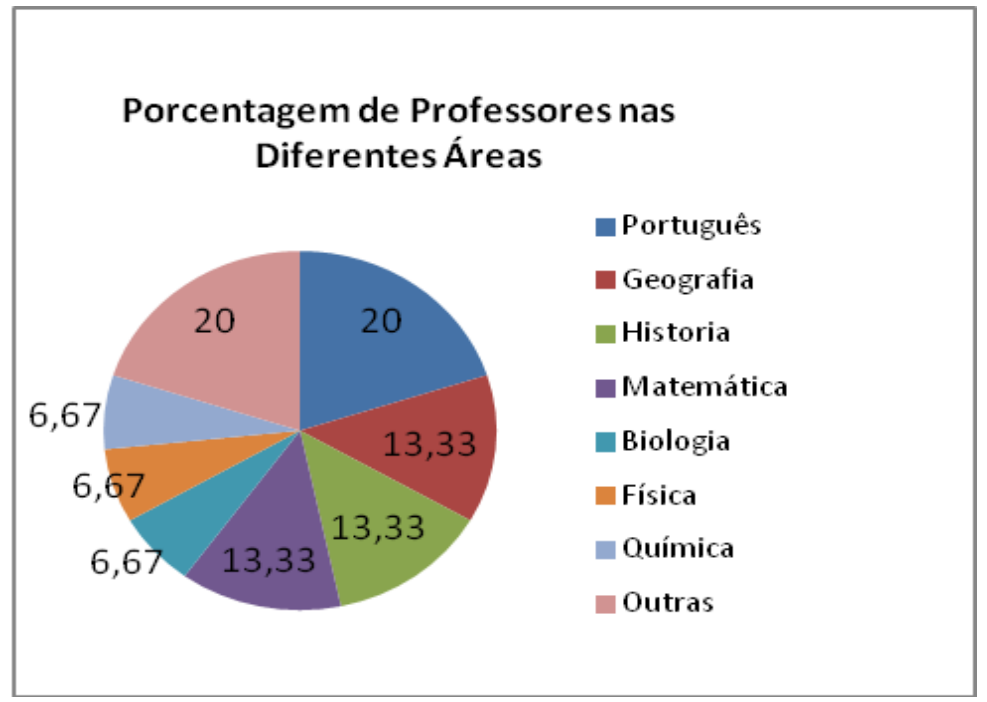

Gráfico 4: Professores em cada área

- Nenhum dos professores trabalha em período integral na escola;

- $60 \%$ dos professores são efetivos, $10 \%$ contratados e $30 \%$ eventuais;

- Apenas 20\% utilizam o computador;

- $70 \%$ dos professores sabem que existem recursos computacionais disponíveis na escola; $60 \%$ disseram que teriam suporte técnico para utilizá-los se desejassem; e somente $50 \%$ disseram ter livre acesso aos equipamentos;

- 70\% dos professores disseram incentivar os estudantes a utilizar computadores em atividades didáticopedagógicas;

- Nenhum professor disse que desconhece a tecnologia de RV; $70 \%$ afirmam conhecer, enquanto 30\% afirmam já terem ouvido falar; 
- Quase a totalidade dos professores acredita que a RV poderia ajudá-los a transmitir a matéria mais facilmente.

\subsection{Questionários de pós-teste}

Após definida a disciplina de Matemática como a que seria abordada pelo projeto-piloto, a escolha pelo conteúdo (geometria espacial) e a transformação do laboratório, foram realizadas as sessões com três professores de Matemática e vinte estudantes.

Os questionários de satisfação (pós-testes) foram aplicados, separadamente, para professores e estudantes.

Os resultados sobre a pesquisa demonstraram que os estudantes aceitaram o aplicativo pela facilidade de uso, motivação, navegabilidade, recursos e clareza nos objetivos propostos pelo software. Todos os entrevistados informaram que voltariam a utilizar o software, o que demonstra que aprovaram a proposta de ensino com o apoio de recursos computacionais.

Os três professores, de modo geral, são favoráveis ao uso de tecnologia nas disciplinas, incluindo-a na matéria que lecionam. Acham positiva a interação dos estudantes com o software e a possibilidade de acesso em ambiente extraclasse (acesso via internet). O conteúdo aplicado através do software complementa o lecionado em sala de aula. Acreditam também que o uso da tecnologia tende a socializar e potencializar o ensino e incentivar a criatividade e aprendizado dos estudantes e pode proporcionar uma troca de experiências entre professores e estudantes.

\section{Conclusões}

Este trabalho apresentou o processo de transformação de um laboratório de Informática pré-existente em um laboratório de RV não imersiva, sem custos adicionais. Através de um estudo de caso foi possível validar o processo apresentado. Vale ressaltar que, por se tratar de um estudo de caso, a mesma abordagem em uma escola diferente poderia ter resultados diferentes como, por exemplo, já possuir professores mais treinados em tecnologia ou ter equipamentos mais atualizados. A seguir são apresentados alguns pontos de destaque deste trabalho:

- Há necessidade da realização de novos projetos como o que foi implementado, principalmente focando o baixo custo em escolas públicas a fim de promover a inclusão digital;

- Há necessidade de se dar capacitação aos professores para que eles possam utilizar e desenvolver projetos das disciplinas que lecionam, introduzindo novas tecnologias;

- Este projeto foi apontado como factível de ser implementado nas escolas com um laboratório de informática já instalado;

- Foi possível avaliar a satisfação dos estudantes e professores em relação à aplicação, fazendo ajustes às heurísticas de Nielsen [26]. Esses ajustes se tornaram necessários visto que estas heurísticas foram concebidas, nos anos 90, para avaliar sistemas $W e b$ que não envolviam tecnologias como RV;

Outros pontos relevantes do projeto foram os resultados das pesquisas com os estudantes que demonstraram e auxiliaram na escolha para implantação do software de Matemática, constatando que a maioria dos estudantes acreditava que o desempenho em Matemática e outras disciplinas melhorariam se obtivessem auxílio tecnológico devido a dificuldades encontradas nos métodos tradicionais utilizados.

Nos testes de utilização do aplicativo, os estudantes consideraram o aplicativo fácil, pois ele reflete um ambiente virtual parecido com o modelo de sala de aula: sala com lousas; além disso, o ambiente possui poucos objetos (metáforas visuais), o que garante que o estudante encontrará as suas funcionalidades rapidamente (design minimalista considerado por Nielsen [25]). A avaliação também identificou que os estudantes consideraram que a aplicação apresentou clareza no objetivo proposto e boa capacidade de navegação.

Todos os envolvidos nesse trabalho aprovaram a proposta de incluir tecnologia no ensino. Os estudantes avaliados pela pesquisa informaram que utilizariam o software novamente, o que reforça a motivação e a necessidade de novos estudos e novos projetos de baixo custo na área educacional. Isso identifica uma 
defasagem de uso de tecnologia, pois embora todos os estudantes queiram utilizar a tecnologia para o aprendizado, apenas $20 \%$ dos professores a utilizam de fato.

A avaliação das pesquisas feitas com os professores demonstrou que um número expressivo conhece RV e tem acesso aos equipamentos ou laboratórios de informática da escola que lecionam. Os professores informaram que têm conhecimento que diversificar a metodologia de ensino pode ajudar a manter atenção do estudante e melhorar o aprendizado principalmente com a inclusão de novas tecnologias.

Na pesquisa de satisfação do uso do aplicativo, que foi desenvolvido para a disciplina de Matemática, os professores avaliados aprovaram a utilização do software. Como pontos positivos as interações dos estudantes com software e o uso de tecnologia na disciplina que lecionam, os professores acharam o conteúdo do aplicativo adequado ao que os estudantes têm em sala de aula, de fácil utilização e motivador. Os professores acreditam que o software auxilia o estudante ao convívio em sociedade e melhora a disciplina, bem como o relacionamento entre estudantes e professores.

Como trabalhos futuros, é proposto o uso e a construção de novos aplicativos para outras áreas do conhecimento e implantação de outros laboratórios. Além disso, propõe-se uma avaliação detalhada e formal dos aspectos pedagógicos do uso de RV na educação.

\section{Referências}

[1] BURDEA, G. C.; COIFFET, P. Virtual Reality Technology, Wiley-Interscience, USA, 400 pages. 1994.

[2] KALAWSKY, R. The Science of Virtual Reality and Virtual Environments, Addison-Wesley Reading, 1993.

[3] VINCE, J. Introduction to Virtual Reality. Springer-Verlag, Germany, 2004.

[4] CARDOSO, A. et al (Eds). Tecnologias para o desenvolvimento de sistemas de realidade virtual e aumentada. Recife. Editora Universitária da UFPE, 2007.

[5] GUIMARÃES, M. P.; GNECCO, B. B. Sistemas de Realidade Virtual e Realidade Aumentada de Baixo Custo. In: A. N. Marana, J. R. F. Brega. (Eds.). Técnicas e Ferramentas de Processamento de Imagens Digitais e Aplicações em Realidade Virtual e Misturada. 1 ed. Bauru: Editora Canal 6, 2008, p. 161-170, 2008.

[6] OLIVEIRA, R. P. Realidade Virtual no Ensino de Física: Explorando o Conceito de Queda Livre. Vol 3 no 1 janeiro/junho de 2010.2010.

[7] JEFFREY, S.; MOORE, A.; PHILIP, A. Chemistry goes global in the virtual world. Nature Chemistry 1, 2 - 4. Disponível em: <http://www.nature.com/nchem/journal/v1/n1/full/nchem.138.html. Acesso em: 17 mar. 2013.

[8] WANG, Y. et al. Virtual Reality Mathematic Learning Module for Engineering Students. Technology Interface Journal, Vol. 10, No. 1, pp 1 - 10. 2009.

[9] KIRNER, C.; SISCOUTTO, R. Eds). Realidade Virtual e Aumentada: Conceitos, Projeto e Aplicações. Livro do Pré-Simpósio. IX Symposium on Virtual and Augmented Reality. Petrópolis. RM, 28 de maio de 2007.

[10] JACOBSON, J. et al, Immersive Displays for Education Using CaveUT. World Conference on Educational Multimedia, Hypermedia \& Telecommunications, Montreal, Canada, June 27-July 2.2005.

[11] DIAS, D. R. C. Avançado de Realidade Virtual para Visualização de Estruturas Odontológicas. Dissertação de Mestrado em Ciência da Computação. Universidade Estadual Paulista Júlio de Mesquita Filho, UNESP, Brasil, 2011.

[12] BLENDER. Disponível em: <http://www.blender.org/>. Acesso em: 16 mar. 2013.

[13] AUTODESK SOFTIMAGE. Disponível em:

$<$ http://usa.autodesk.com/adsk/servlet/pc/index?id=13571168\&siteID=123112>. Acesso em: 11 mar. 2013

[14] CINEMA 4D. Disponível em: <http://www.maxon.net/>. Acesso em: 10 mar. 2013.

Revista Brasileira de Computação Aplicada (ISSN 2176-6649), Passo Fundo, v. 5, n. 1, p. 98-112, abr. 2013111 
[15] 3DS MAX PRODUCTS. Disponível em: <http://usa.autodesk.com/3ds-max/>. Acesso em: 10 mar. 2013.

[16] MAYA. Disponível em: <http://usa.autodesk.com/maya/>. Acesso em: 17 mar. 2013.

[17] PANDA3D. Disponível em: <http://www.panda3d.org/>. Acesso em: 14 mar. 2013.

[18] OGRE - Open Source 3D Graphics Engine. Disponível em <http://www.ogre3d.org/>. Acesso em: 11 mar. 2013.

[19] MARTINS, V. F.; GUIMARÃES, M.P. Desafios para o uso de Realidade Virtual e Aumentada de maneira efetiva no ensino. In: DEsafIE! - I Workshop de desafios da computação aplicada à educação - XXXII Congresso da Sociedade Brasileira de Computação, 2012, Curitiba. Anais do DEsafIE! - I Workshop de Desafios da Computação Aplicada à Educação, 2012.

[20] FREIRE, P. Educação e Mudança, Editora Paz e Terra, 2011.

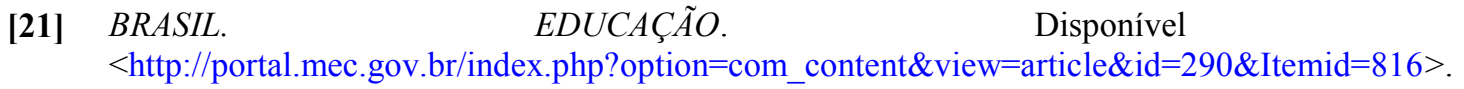
em: Acesso em: 14 mar. 2013.

[22] SANTOS, A. D.; MACHADO, L. S. Visualização Tridimensional de Baixo Custo para o Desenvolvimento de Aplicações em Medicina. In: Workshop de Realidade Virtual e Aumentada, Itumbiara. Anais do Workshop de Realidade Virtual e Aumentada, p. 1-4 , 2007.

[23] KELLER, R. \& SCHREIBER, J. N. C. Geo-3d: A Realidade Virtual como suporte ao Ensino da Geometria Espacial. In: II Workshop Brasileiro de Realidade Virtual, 1999, Marília. Anais do II Workshop Brasileiro de Realidade Virtual, 1999. p. 182-193.

[24] SHUMAKER, R. Virtual Reality: Second International Conference, ICVR 2007, Springer, 2007, pp. $244-252$.

[25] NIELSEN, J. Heuristic Evaluation. In: J. Nielsen (ed.) Usability Inspection Methods. John Wiley, New York, 1994.

[26] LIKERT, R. A Technique for the Measurement of Attitudes. Archives of Psychology 140: pp.1-55, 1932. 